\title{
Exploring Learning Analytics in College English Teaching and Learning in Big Data Era
}

\author{
Yanghua Peng \\ School of Foreign Languages \\ Chengdu College of Arts and Sciences \\ Chengdu, China \\ E-mail address: pengls@126.com
}

\begin{abstract}
The research tries to explore new college English teaching and learning modes based on learning analytics in Big Data Era. Under the theories of second language acquisition and learning analytics, this article holds that it is vital and indispensable to apply learning analytics to college English teaching and learning based on the two typical cases of wide application of Corrects a Cool Web at colleges and universities and the pilot project---the blended teaching and learning method conducted at University of Electronic Science and Technology of China. With the help of the software such as Lanmuyun, ISmart, researcher can get more scientific and effective data to promote personalized learning activity and also optimize teaching modes and teaching methods as well. The paper ends with some implications of the present research for college English language teaching and learning in China.
\end{abstract}

Keywords-Learning Analytics; College English Teaching and Learning; Big Data Era

\section{INTRODUCTION}

The Ministry of Education issued "Education Informationization 'The thirteenth Five-Year' Plan" in 2016. The Plan puts forwards explicitly that it is vital to apply information technology to education and try to realize education informationization. Teaching and learning will be optimized, management meticulous and decision scientific in this way. Currently information technology and education become increasingly integrated in Big Data Era.

In the era of big data, learning analytics has become a research focus in academia. For several years, the United States New Media Consortium (NMC) consider learning analytics as the crucial factor which influences education development. The United States NMC predict that learning analysis will become the mainstream of research in the field of education, and the International Conference on Learning Analytics and Knowledge (LAK) also provide the organizational guarantee for the research[1]. Many Chinese scholars such as Wu Yonghe, Han Shun Ping, Zhang Jiahua, Zou Qin, and Zhu Zhiting have done some theoretical research work in this field[2-3]. But learning analytics employed in college English teaching and learning is a complete blank [4].

With the rapid development of information technology, college English teaching and learning meet unexpected challenges. The traditionally teacher-centered teaching modes

Sponsored by the program" Exploring College English Teaching and Learning Mode based on Learning Analytics in Big Data Era" and face-to-face methods in classroom are challenged seriously by these various net-based E-learning, E-communication and E-university and so on. Traditional teaching methods cannot satisfy learners' personalized learning any more. New technologies such as mobile technology, intelligentization and virtual reality technology call for new teaching and learning modes and methods accordingly. These newly net-based teaching and learning modes focus on students-centered pattern instead of teacher-centered one, which emphasize the flexibility and convenience while integrating the content of the course and technology. In Big Data Era, mass data are distributed in students' information systems, course management systems, learning management systems, on-line learning resources and students' community social network. This article holds that it is vital and indispensable to apply learning analytics to college English teaching since it can provide valuable data scientifically and effectively to promote personalized learning activity and also optimize teaching modes and methods as well. The research try to explore a new college English teaching and learning mode based on learning analytics in Big Data Era. The paper ends with some implications of the present research for college English language teaching and learning in China.

\section{LEARNING ANALYTICS}

Siemens, a leader in learning analytics, defines the learning analytics as the measure, the collection and the report of data of the students performance and the conditions of their studies[5]. To put it another way, data model is established which occurred in the learning process and various methods are employed to explore the value of big data that is hidden in learning activity. Factors such as course content, teaching environments and teaching evaluation and so on are taken into consideration to construct the analyzing mode involved in instructors, students, managers, and learners. Suthers \&Verbert point out learning analytics is the third wave of education informationization and the specific application of analytics technology in the field of education.

Brown divided the constituting elements of learning analytics into five categories: data collecting, data analyzing, students learning, benefited community and interfering measures[6]. And these data comes from education system and learning environments. Data collecting includes data of learning management system and data journal of students' 
activities in information system, which exists in the channel of on-line learning resources and social media and mobile termination [7]. With the learning resources going into Clouds increasingly, quantitative data will increase definitely. The ideal condition of learning analytics is to integrate the data, to analyze the structural and nonstructural data, to give a timely feedback and to provide a learning scaffolding [8]. Combined quantitative with qualitative analysis, the analyzing results are presented to benefited community in forms of visualization, tables and figures and things. Students learning will be concentrated on the interactive data stream of students and learning environment, which includes the interaction with education resources, the socially metric index, emotion, performance, learning media. It offers a dependable and objective feedback and improves the learning efficiency. And the main benefited community are composed of students, teachers, teaching designers, educational institutions. However, their needs for information are quite different. Roughly speaking, students need relevant feedback on their actual performance, content and learning strategies to optimize their learning. For teachers, they are eager to improve the teaching practice by following the data trace. With the aid of analyzing data, teaching designers evaluate the learning materials, adjust the level of difficulty and upgrade the quality of courses. Finally, the educational institutions take the advantages of the data and make the best of the educational resources to improve the personnel training. Last but not least, interfering measures grow out of aiding data-based teaching and learning. They emphasize effective and guiding teaching activities based on scientific data. Their ultimate goal is to supervise, analyze, predict, interfere, evaluate, respond, reflect and optimize the learning activities[7].

\section{ApPLiCATION OF LEARNING ANALYTICS IN COLLEGE ENGLISH}

The typical case analysis of learning analytics is the application of Corrects a Cool Web, an online service system researched and developed independently by Beijing Ciwang Science and Technology Ltd, .Co. Based on corpus and Cloud computing technology, it offers on-line correcting service and presents timely students' score, remarks and comments, which arouse students' interest and enthusiasm to better their composition. Meanwhile, teachers can get to know how the students' compositions are intuitively and in this way teachers' work efficiency are enhanced.

Writing composition once became a torture for both teachers and students. Roughly in China faculty-student ratio is 1 to 130 and teachers have no enough time to correct students' compositions one by one. Even with hard work, all the compositions have been completed. Teachers feel exhausted and students cannot get a timely feedback. Most of the students just get back the compositions from teachers and have no motivation and confidence to better their compositions consciously. This terminal evaluation methods hardly measure students' developing trace and imply the students' implicit learning aptitude impossibly so they can not satisfy students' personalized learning. Therefore poor performances in writing compositions happen in tests, which can be easily found in College English Test Band 4. To cope with the problem,
Corrects a Cool Web appear. It is superior to teachers' correcting in the aspects of openness, flexibility, convenience and so on. This web assists teachers in correcting English composition, which relieves teachers' heavy burden and improves students' writing abilities. Researchers in Najing University conduct a survey from 1456 samples of writing composition in 2010 final examination. They find that concordance rate between manual work and computer selfcorrecting is up to 92.03 percentage. Compared with E-Rater, Corrects a Cool Web has reached advanced international standards. With these well-proven advantages, the web is widely employed at colleges and universities.

Corrects a Cool Web sets a very good example to aid improving college English teaching and learning based on data, and also it shows its powerful potentiality of learning analytics. This web makes a developing and processing instead of terminal evaluation and supports real-time assessment by analyzing the data traced back to the writing platform. Students come to realize their shortcomings and are willing to improve themselves in writing composition consciously. Selfquantitative analysis correspond to the natural demands to recognize themselves from outside. Employing learning analytics, Corrects a Cool Web explores each individual's informal learning performance and produces corresponding report by data mining and visualization analyzing. Students from different majors and different levels interact with technology mutually to satisfy their learning desire and emotional needs, and they are willing to experience the pleasant learning activity as well. Furthermore, the learning environments have been changed under the condition of Corrects a Cool Web, which make writing flexible and convenient without time and space limitation. There are many advantages of Corrects a Cool Web and space lacks for a detailed description of it. Finally, Corrects a Cool Web provides powerful data supported by diagnosing students' writing problems, analyzing large quantity of real data to know learners' individuality and commonness. And teachers also reflect on their teaching methods and adjust their teaching modes by following and examining students' learning trace.

Another case analysis of learning analytics is the application of blended teaching and learning mode employed by researchers University of Electronic Science and Technology of China. And this kind of mode has been carried out successfully at this university. Work is done from the following two aspects: teaching goal design, course content design. While setting teaching goals, some theories of behaviorism, cognitivism and constructivism are taken into consideration. The teaching design are divided into three levels: overall design, successive design and specific design. It can be decomposed into a book, a unit and even a class. As far as course content design is concerned, four stages become critical. They are teaching resources, teaching methods, teaching steps and teaching evaluation. All these preparation work must be well-done ahead of time. In order to get more reliable data, help can be gotten from some software platforms. Lanmoyun, a name of software, is employed in the warm-up part of a text. For example, vocabulary quiz on Lanmoyun, 20 items within about 15 minutes are required to complete. On this platform, we can easily monitor how the students finish their work. This 
kind of way here can be called on-line and off-line teaching and learning method. While carrying out the plan of the course content, teachers' instruction and students' participation are asked to be numbered especially the latter get more attention. Students' performance in each stages will be scored, which constitute their final score in the term. Teachers play quite different roles at different stages and they may be instructors, monitors, participants and things. This is called the combination of teachers' instruction with students' participation. Eventually, teachers will give some assignments to students such as letter writing, a small project like debate and so on. These assignments are closely related to the course content. If students miss one class for some reason, they can hardly make it up after class. In-classroom and out-classroom are closely connected and mixed up sometimes. Similarly, it also has been proved that this type of blended teaching and learning mode is still applicable to poor students at low level. The main reason is that the data -based learning analytics can provide valuable data scientifically and effectively to promote personalized learners' learning activity.

\section{CONCLUSION}

From all mentioned above, especially the two typical case analysis of learning analytics---the application of Corrects a Cool Web and blended teaching and learning mode tell us the intellectual technology has become a leading force which changes human's life and way of learning of course. Meanwhile, the intellectual technology must bring about profound and strategic breakthrough in foreign language teaching and learning. Inspired by these, researchers and teachers are expected to try to explore more college English teaching and learning modes in Big Data Era.

Obviously, all the data -based activities facilitate students to learn English more actively and the reliable data and results will make teachers and students more convincing. Since databased learning analytics can provide valuable data scientifically and effectively to promote personalized learners' learning activity and also optimize teaching modes and methods as well, this paper strongly recommends learning analytics technology and cries for its application to college English teaching and learning.

\section{ACKNOWLEDGMENT}

I would like to take this opportunity to thank those who have given much help to me. First and foremost, sincere thanks and gratitude to Linbing Yao who deserves a great deal of thanks for his help and encouragement. Appreciation is also expressed to Weimin Wang for always being kind, understanding, and helpful during the undertaking of the work. Finally, thanks will go to my family for their support and love.

\section{REFERENCES}

[1] Cao Shuai,Wang Yining, Xu Peng, "The current situation and future trend of learn analysis technology based on 2011---2015 LAK conference papers. " China Educational Technology, 2016. ((In Chinese)

[2] Zhang Jiahua, Zou Qin, Zhu Zhiting, "A Visualization Analysis of Domestic Research on Learning Analytics during the Past Five Years, " J. Journal of Zhe Jiang Normal University, 2017. ((In Chinese)

[3] Zhu Zhiting, Shen Demei, "A New Research Normal Form of Educational Technology Based on Big Data, J. A research of Educational Technology, 2013. ((In Chinese)

[4] Gan Ronghui, He Gaoda, "Exploring Learning Analytics in Foreign Language Teaching in Big Data Era, " J. Educational Technology for Foreign Language Teaching, 2016. ((In Chinese)

[5] Siemens, G. "Learning analytics: The emergence of a discipline, " J. American Behavioral Scientist, 2013 (57).

[6] Brown. M, "Learning analytics: Moving from concept to practice," J. EDUCAUSE Learning Initiative, 2012(7).

[7] Chatti,M. A, Dyckhoff, A. L, and Schroeder, U, "A reference model for learning analytics." International Journal of Technology Enhanced Learning, 2012 (4)

[8] Fiaidhi,J. "The next step for learning analytics." The IEEE Computer Society, 2014 (16) 